\title{
Pobladores. Luchas sociales y democracia en Chile
}

\section{François Dubet, Eugenio Tironi, Vicente Espinoza y Eduardo Valenzuela}

\author{
Chile, Ediciones Universidad Alberto Hurtado, 2016, \\ 232 páginas.
}

\author{
Constanza Escobar Arellano \\ Universidad Alberto Hurtado, Santiago, Chile. \\ Email: constanza.escobar.a@gmail.com
}

“Pobladores. Luchas sociales y democracia en Chile” se inscribe en una tradición investigativa que, siguiendo los planteamientos de Touraine, estudia los movimientos sociales mediante la metodología de intervención sociológica. Exponentes de esta tradición se unen en alianza estratégica para desarrollar este esfuerzo por conocer la posibilidad de los pobladores del Chile del segundo lustro de los 80' de convertirse y actuar como un movimiento social con la capacidad de hacerle frente o derrocar a la dictadura. Así, la línea de investigación ya desarrollada a nivel nacional por los sociólogos del centro de investigación social SUR, Eugenio Tironi, Vicente Espinoza y Eduardo Valenzuela, centrada en militantes pobladores y democratización, se combina con la mirada de CADIS, fundado por Alan Touraine, que desde Francia y materializada en la figura de François Dubet venía desarrollando investigaciones con la aproximación de intervención sociológica desde la década de los 70’: el movimiento estudiantil en Francia, las luchas antinucleares, las luchas regionalistas, el movimiento solidaridad en Polonia, entre otros.

El libro, da cuenta de la investigación realizada por Dubet, Tironi, Espinoza, Valenzuela, Saball y Echeverría con pobladores en la ciudad de Santiago entre 1985 y 1986. Publicada originalmente en francés por la editorial L'Harmattan el año 1989, es reeditada por primera vez en castellano por Ediciones Universidad Alberto Hurtado en 2016. Pobladores, en su versión original se compone de 11 capítulos organizados del siguiente modo. El capítulo I problematiza, caracteriza y define el sujeto de estudio, los pobladores, para luego en el capítulo II abordar diversas teorías de la marginalidad para conceptualizarlo, concluyendo el relegamiento de la visión de la marginalidad a una teoría de alcance medio. El capítulo III trata sobre el modelo de análisis construido a partir de la combinación de dos ejes; explotación/ exclusión y participación/ ruptura, que sirven para construir el siste- 
ma de acción de los pobladores a partir de cuatro lógicas de acción, que se definen entre los capítulos IV y VII: la acción reivindicativa, la participación populista, la defensa de la comunidad y la ruptura revolucionaria. El capítulo VIII presenta el argumento central, al plantear que no existe un movimiento de pobladores sino que se observa "una dispersión indefinida de lógicas de acción que ninguna fuerza interna articula” (Dubet, Tironi, Espinoza y Valenzuela, 2016, p. 160). Luego, el capítulo IXanaliza la relación entre los militantes en organizaciones de pobladores y la base a la que representan, con diversas conductas y las consiguientes tensiones. El capítulo X detalla la historia de las luchas sociales de los pobladores y el predominio de ciertas lógicas de acción en cada período, para en el capítulo XI problematizar la situación nacional de la época, y la posibilidad de un retorno a la democracia de cara al plebiscito del 88, aun sin la emergencia de una figura que aglutine y encarne una opción al combate contra la dictadura. Después de la conclusión se adjunta un anexo metodológico que permite aproximarse a los principios y métodos de análisis de la intervención sociológica y su aplicación en el estudio de pobladores en Santiago.

A lo anterior, la reedición suma una introducción a cargo de Alexis Cortés y cuatro postdatas retrospectivas, que elaboradas a 30 años de haberse desarrollado la investigación aportan con una mirada lúcida a aspectos relevantes de la publicación original. Así, Dubet en la postdata 1 detalla el método de intervención sociológica, en tanto Tironi en la postdata 2 revisita las consecuencias políticas de la investigación y enlaza la metodología con los Foros Híbridos de Latour y la teoría actor red (ANT). Espinoza, en la postdata 3 pone en perspectiva, bajo una mirada crítica,el estudio, sus resultados y aborda la vigencia del análisis. Finalmente, Valenzuela en la postdata 4 releva el tránsito de los movimientos de protesta, en el contexto de las transformaciones sociales que han sucedido posterior a la investigación realizada.

Los resultados son paradójicos y concluyentes en un doble sentido. Paradójicos tanto porque la utilización de un método especialmente diseñado para el estudio de movimientossociales no logra sino demostrar lo contrario, la ausencia de un movimiento de pobladores (lo que a juicio de los autores remarca la robustez del método y del equipo investigador), como porque el resultado contrario a lo esperado impacta también en las lógicas con las que enfrentar la salida a la dictadura y entrar en un período democrático. Y es que justamente la investigación realizada tenía un propósito normativoal buscar constatar la posibilidad de que desde el sector marginal de la sociedad emergiera el potencial de acción movilizadora para derrocar la dictadura, dadas las protestas emergentes con fuerza en los primeros años de los $80^{\prime}$.

Sin embargo, la fuerza de los resultados (bajo el soporte de la mirada experimentada de Dubet) confronta la premisa inicial. Los pobladores son un grupo heterónomo, que carece de una mirada común y la capacidad de articular un proyecto social propio y pasar a la estrategia política. Según afirman, 
"No puede haber movimiento social de pobladores si lo que se entiende por este concepto es una acción colectiva organizada alrededor de un conflicto de clase, identificado con un proyecto de organización de la sociedad y de su desarrollo enfrentado al de las clases dirigentes. (...) El movimiento de los pobladores no tiene un principio central, es una "suma” de reivindicaciones, de participación populista, de afirmación comunitaria y de voluntad de ruptura. Es un balance entre dependencia y autonomía.” (Dubet et alia 2016, p.210).

En cambio, el sector se mueve por las cuatro lógicas de acción identificadas, las que actúan en confluencia e imbricación a lo largo del período estudiado (desde los cincuenta hasta fines de los ochenta). Y si bien, en cada momento histórico algunas adquieren más vigor que otras, en general se dan interconectadas.

Otro de los aspectos centrales del libro, es la relevancia que avizora en el ámbito religioso como eje aglutinador de un sentido común. Ante el declive de otros elementos capaces de unificar un auto reconocimiento y definición, la religión cobra fuerza y permea discursivamente en los militantes participantes del estudio con términos como salvación, pueblo de Dios, castigo, por ejemplo. Este resultado, aunque no novedoso, no es menor ya que, como plantea Tironi en la postdata 2, este sentido sirvió de base para la elaboración de la estrategia político-comunicativa con la que enfrentar el plebiscito de 1988 en la campaña del No, al posicionarse como "profetas de la esperanza” y desde esa lógica mesiánica luchar contra el miedo y sentido de vulnerabilidad producto del poder absoluto del Estado, como constataba la investigación.

Y aquí se enlaza otra de las consecuencias principales del trabajo, la influencia política y metodológica.

A nivel político, sus resultados fueron fundamentales para el abordaje del proceso de transición democrático, en tanto la inexistencia de un movimiento social que pudiera por sí mismo articular y fracturar una dictadura que a la fecha de la publicación parecía resistir todo esfuerzo por hacerle mella, obligaba a pensar una salida institucional, carente de actores en el plano social, con la consecuente exclusión de estos grupos durante el período de transición.De este modo, se fragua una salida conformada por una coalición de fuerzas políticas que se enlazan ante el fin último de lograr retomar la democracia, en la que Tironi, uno de los autores, toma un rol preponderante, demostrando con ello además cierta instrumentalización de los resultados con fines políticos. Cierta, porque en alguna medida el sentido del estudio ya poseía en su génesis fines políticos.

Sin embargo, la radicalidad del argumento resulta controversial, y autores como Salazar (2012) confrontan estos postulados, desde una perspectiva historiográfica. Por una parte, pone en cuestionamiento la producción académica sobre movimientos sociales desde Europa y Estados Unidos, planteándose "si los movimientos sociales reales deeste continente 
requieren de ese tipo de teoría” (Salazar, 2012, p. 406). Por otra, argumenta que el equipo investigador, a modo de una suerte de Touraine's boys (en analogía a los Chicago boys) se vale de este estudio para legitimar teórica y políticamente la nueva democracia pactada, deteniendo la teorización sobre el movimiento social y la implicación de sus actores en esa transición. De este modo, como señala:

"El avance de la teoría de los MS fue frenado en Chile, por tanto, primero, por el peso de la tradición estructural-funcionalista entre los sociólogos y el peso de la tradición marxista-leninista entre los historiadores de izquierda y, después, por la interferencia políticopragmática de la 'teoría' de la transición negociada a la democracia.” (Ibíd. p. 441)

De este modo, no es menor el efecto performativo y normativo que tuvo el estudio, que vuelve actual su debate y que dio pie al proyecto FONDECYT de iniciación 11140336 (2014-2016): "SUR y la construcción del anti-movimiento de pobladores: ciencias sociales, performatividad y movimientos sociales en Chile 1985-1995”, desarrollado por Alexis Cortés y en cuyo marco emerge esta reedición. En este sentido, y como plantea en el prólogo, es central el contexto de realización, al situarse “en un momento clave para la definición de las estrategias de recuperación de la democracia en Chile” (Dubet et alia, 2016, p.11).

A nivel metodológico, el desarrollo de la intervención sociológica es también notable. Si bien ha sido ampliamente desarrollada por sus creadores, a nivel nacional e incluso latinoamericano su abordaje ha sido escaso, por lo que Pobladores, es un buen ejemplo de utilización. Y es que su réplica es compleja y además costosa; como plantea Dubet, requiere de participantes dispuestos a desarrollar una serie de sesiones de diálogo y construcción de sentido intersubjetivo, la formación de un equipo investigador en la metodología (ya que sería una empresa prácticamente inabordable para un único investigador) dispuesto a poner en juego sus propias interpretaciones, al someterlas al cuestionamiento del grupo de actores participantes e interlocutores.

El método se basa en una teoría de acción social en que los movimientos sociales se definen por una forma de conciencia caracterizada en tres dimensiones: la identidad, como la forma en que los actores se definen a sí mismos en función de dimensiones que ellos movilizan en su acción; el principio de oposición, mediante el que los actores se definen en contra de sus adversarios o de mecanismos sociales que se oponen a sus proyectos; y el principio de totalidad (enjeux), como el control de sus relaciones.

En su aplicación, consiste en la construcción artificial de pequeños grupos, compuestos por participantes del movimiento (que en ningún caso actúan como representantes de éste) para “emprender un autoanálisis de las prácticas en las que participan, y, por esta vía acceder a conocer relaciones sociales que no están en la superficie” (ibíd., p.26). Durante las sesio- 
nes, los participantes se confrontan a los interlocutores (aliados o adversarios a sus proyectos) además de a los investigadores (intérprete/aliado y analista/adversario). Y si bien fue diseñado especialmente para estudiar los movimientos sociales, su práctica ha llevado alejarse de este foco para "comprender cómo se construye la experiencia más banal de los actores sociales” (ibíd.p. 20), como menciona Dubet en su post data.

Sin duda, este libro se convierte en una pieza relevante de investigación sociológica que cobra actualidad en la lectura y puesta en cuestión de los movimientos sociales hoy y cuyo método podría entregar piezas de análisis claves para entender períodos de efervescencia popular como el movimiento estudiantil de 2011, las manifestaciones “NO+AFP” del 2016 o la movilización feminista que en estos momentos se alza con fuerza. 


\section{Referencias}

Dubet, F., Tironi, E., Espinoza, V., y Valenzuela, E. (2016).Pobladores: Luchas sociales y democracia en Chile. Santiago, Chile: Ed. Universidad Alberto Hurtado.

Salazar, G. (2012). Movimientos sociales en Chile. Santiago, Chile: Uqbar Editores. 